\title{
Characteristics of Recycled Aggregate Concrete Produced with Crushed Stone Sand as Fine Aggregate
}

\author{
Roz-Ud-Din Nassar \\ Department of Civil and Infrastructure Engineering, American University of Ras Al Khaimah (AURAK), \\ United Arab Emirates (UAE)
}

Received May 11, 2020; Revised July 23, 2020; Accepted August 10, 2020

Copyright $@ 2020$ by authors, all rights reserved. Authors agree that this article remains permanently open access under the terms of the Creative Commons Attribution License 4.0 International License

\begin{abstract}
In this work the characteristics of recycled aggregate concrete produced with crushed stone sand as $100 \%$ replacement of desert stone were experimentally investigated. Concrete mixtures incorporating varying percent replacement of normal aggregate with recycled aggregate as coarse aggregate and crushed stone sand as fine aggregate were produced and tested at 7, 28, 56 and 90 days of concrete age for various hardened concrete properties. For one-on-one comparison, corresponding recycled aggregate concrete mixtures using desert sand as fine aggregate were also tested. Superior performance of crushed stone sand-based concrete mixtures was recorded for compressive and flexural strengths, static modulus of elasticity, abrasion resistance and water absorption characteristics when compared with that of the corresponding recycled aggregate concrete mixtures produced with desert sand as fine aggregate. No significant effect of crushed stone sand was recorded on the split tension strength of concrete mixtures. Improvement in mechanical properties and water absorption characteristics of crushed stone-based mixtures was, however, observed up to 50 wt.\% replacement level of normal aggregate with recycled aggregate. Beyond this level of replacement, no noticeable difference in the performance of the two categories of recycled aggregate concrete mixtures was recorded. It is concluded that crushed stone sand can be effectively used as fine aggregate replacing desert sand to avoid the limitations caused in the mechanical properties of recycled aggregate concrete mixtures due to the use of desert sand as fine aggregate.
\end{abstract}

Keywords Recycled Aggregate, Crushed Stone Sand, Mechanical Properties, Abrasion Resistance, Water Absorption

\section{Introduction}

Concrete is the largest man-made material consumed by humankind with annual global consumption of 12 billion tons $[1,2]$. By volume $70 \%$ of concrete comprises of aggregate [3, 4]. In view of the depleting aggregate sources in some regions and to meet the increasing demand of aggregate necessitated by the increase in concrete consumption, it is essential to look for alternate sources of aggregate other than natural aggregate (NA). Over the years, the use of demolished concrete as recycled aggregate (RA) for production of new concrete has turned out to be a viable choice [5-9]. It has been reported that globally about 900 million tons of construction and demolition (C \& D) waste is generated annually [10]. Such a huge quantity of $C \& D$ waste if used for partial or full replacement of virgin aggregate in the form of RA in concrete production will not only reduce the use of virgin aggregate but will also divert a huge quantity of this resource from landfills to its environmentally friendly consumption in concrete. The use of RA for production of quality concrete has, however, associated challenges to be overcome. For example, fluctuations in its quality, grading issues, and more importantly the attachment of old porous mortar / paste with it are some of the issues to be overcome [6, 11, 12]. The well-known problems linked with the use of RA in concrete is its higher moisture absorption and the consequent large level of drying shrinkage of the resulting concrete called recycled aggregate concrete (RAC). The higher level of drying shrinkage of RAC results in its inferior strength and durability characteristics when compared with that of traditional concrete mixtures [7, 13-16]. Over time, these limitations have hindered the wide use of RA as partial replacement of NA. The use of supplementary cementitious materials in RAC mixtures have offset these 
limitations to a considerable extent resulting in enhancement of strength and durability characteristics of such concrete mixtures [7, 17, 18]. Consequently, it has been made possible to produce RAC mixtures of comparable quality to that of concrete mixtures produced using NA [4, 7, 12]. The use of RA in concrete is associated with important energy and environmental advantages a practice that is viewed to be according to the principles of sustainable development [12, 19, 20].

On the other hand, desert sand (dune sand) is generally used as fine aggregate for concrete production in the Gulf region and North African countries as it is abundantly available in these parts of the world. The use of desert sand in concrete, however, results into a number of disadvantages when the mechanical and durability properties of the resulting concrete are compared with that of conventional concrete [21-23]. Desert sand (DS) particles are smooth, its particle size distribution is very narrow, and it has high surface area [24, 25]. Furthermore, on average 86 wt.\% of DS particles are smaller than 0.25 $\mathrm{mm}$ which corresponds to very small value of fineness modulus of the material [25]. All of these characteristics of DS result in concrete production which has lower strength and higher moisture absorption characteristics. Besides, the use of DS as fine aggregate in concrete results into production of an uneconomical concrete mixture because a large number of sand particles are required to be coated with cement paste in a unit mass of concrete owing to the large surface area of DS [3, 24, 26-28]. It is due to these reasons that some countries in the Gulf region are required to import sand for the construction of sophisticated projects [29]. The situation therefore demands to look for alternate sources of fine aggregate. One such resource is the use of crushed stone sand (CSS) as fine aggregate in concrete replacing DS partly or fully. CSS is obtained during the comminution of rocks into crushed aggregate in aggregate crushing plants. Mostly, CSS is used either as road fill material or for the construction of embankments. However due to its coarser particle size in comparison to that of DS, it is found to be a valuable material for production of concrete having superior quality than the one produced with DS. The use of CSS in concrete will also be beneficial from the stand point of not only a quality construction material but also as a mean of preserving the scarce good quality-sand. The practice, thus results into value-added use of a by-product for the production of economical concrete that also meets the requirements of a sustainable construction practice. Specially, when used in combination with RA, the resulting concrete will turn out to be a completely green concrete. Limited number of studies are available on the use of CSS in concrete [30-33]. However, to the best knowledge of the author no investigation has been carried out on the use of CSS for the production of RAC in the past.

In this paper, the characteristics of recycled aggregate concrete mixtures produced with crushed stone sand as fine aggregate (CS-based mixtures) in fresh and hardened states have been evaluated and compared with that of recycled aggregate concrete mixtures produced with desert sand as fine aggregate (DS-based mixtures). The aim of experimental investigation focused on the evaluation of mechanical properties and water absorption characteristics of CS-based mixtures and their comparison with the corresponding DS-based mixtures. Concrete mixtures produced with $100 \%$ NA with DS or CS used as fine aggregate were produced to serve as control mixtures.

\section{Research Significance}

Experimental investigations on the use of CSS as an alternate source of DS for production of RAC mixtures have been carried out in this work. For this purpose, the strength and durability performance of CS-based mixtures were evaluated and compared to that of DS-based mixtures. It is to be noted that CSS particles have rough and angular geometry, are coarser and free of organic impurities. Because of a wide range particle size distribution, when used in concrete, CSS achieves maximum packing density of the mixture and forms a denser concrete matrix resulting into strength and durability enhancement of the resulting CS-based concrete mixtures. The benefits realized from the use of CSS as fine aggregate in the resulting RAC mixtures shall partially offset the weak microstructure formed due to the presence of RA in such concrete mixtures. Findings reported in this work are expected to pave the way for large-scale use of CSS in the production of RAC.

\section{Materials and Methods}

\subsection{Materials}

CSS was obtained from a local aggregate crushing plant. Similarly, DS was supplied from one of the local quarries. RA with a maximum size of $19 \mathrm{~mm}$ was procured from the local recycling agency. Commercially available ASTM Type 1 cement was used as binder in the experimental program. Water reducing agent of hydrocarboxylic type was used to achieve a target slump of 50 to $75 \mathrm{~mm}$. Figure 1 shows views of DS, CSS, RA and NA while Table 1 presents the physical properties of the ingredient materials used in experimental program. Figure 2 shows the scanning electron microscopic (SEM) image and energy dispersive spectra (EDS) at the location of interfacial transition zone (ITZ) of an RA particle. 


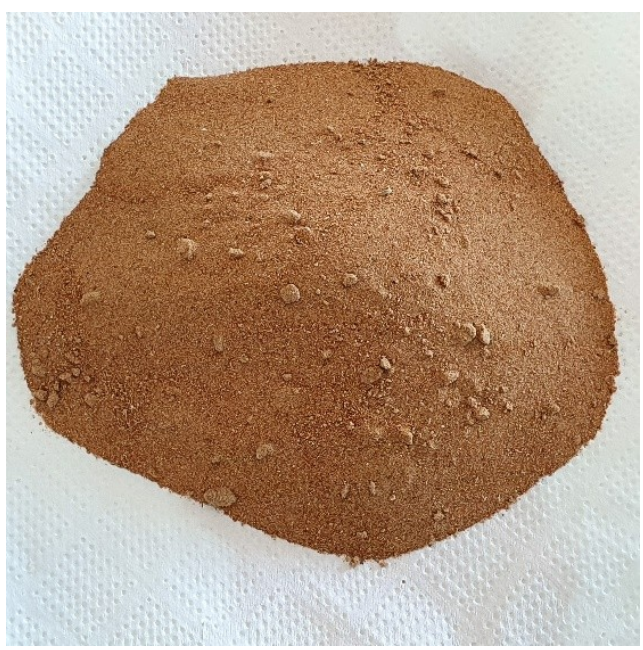

(a)

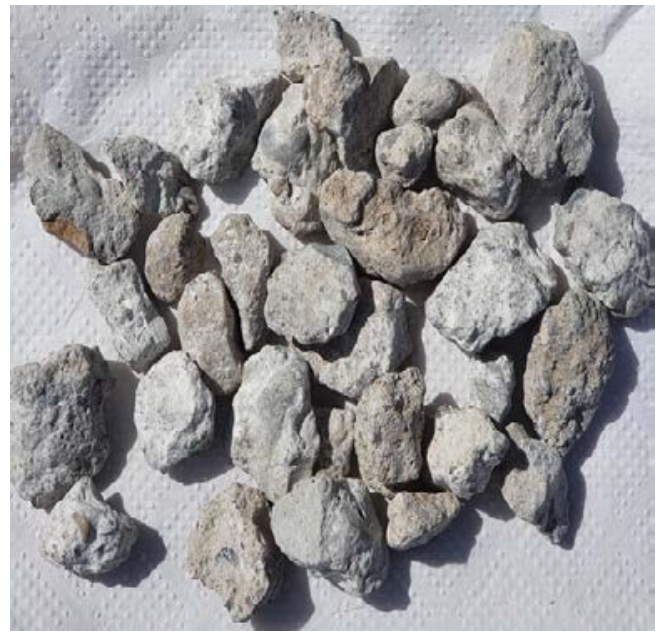

(c)

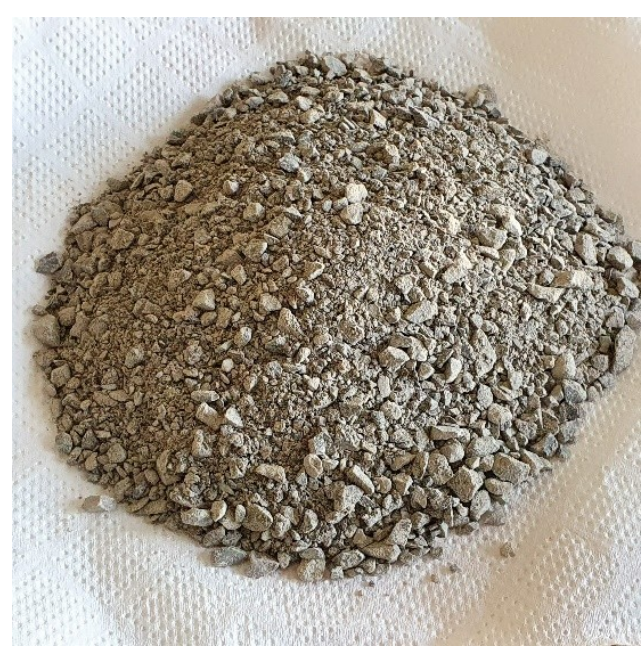

(b)

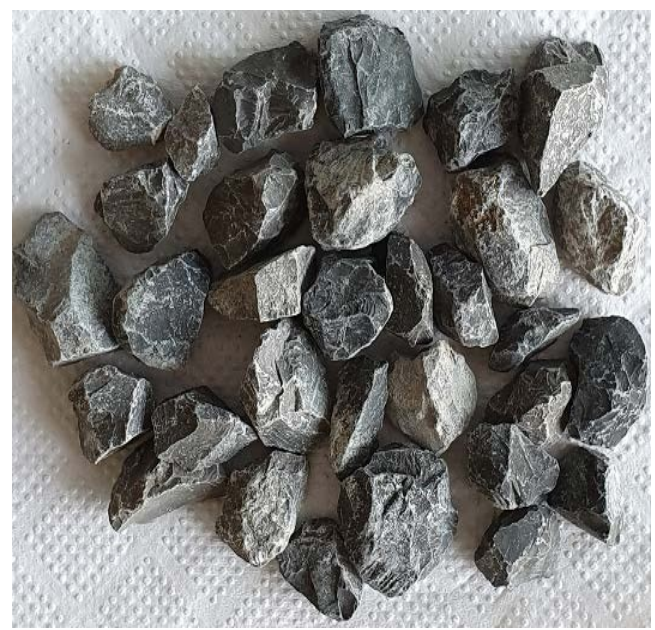

(d)

Figure 1. (a) Desert sand (b) Crushed stone sand (c) Recycled aggregate (d) Natural aggregate

Table 1. Physical properties of NA, RA, CSS and desert sand

\begin{tabular}{|c|c|c|c|c|c|}
\hline Ingredient & $\begin{array}{c}\text { Specific } \\
\text { gravity }\end{array}$ & $\begin{array}{c}\text { Water } \\
\text { Absorption (\%) }\end{array}$ & $\begin{array}{c}\text { Bulk density } \\
(\mathrm{kg} / \mathrm{m} 3)\end{array}$ & $\begin{array}{c}\text { Fineness } \\
\text { modulus }\end{array}$ & $\begin{array}{c}\text { Los Angeles } \\
\text { Abrasion \% }\end{array}$ \\
\hline Normal aggregate & 2.643 & 1.087 & 1590.79 & 6.8 & 19.7 \\
\hline Recycled aggregate & 2.459 & 3.286 & 1493.88 & 5.9 & 26.9 \\
\hline Crushed stone sand & 2.74 & 1.592 & 1461.68 & 3.6 & - \\
\hline Dessert sand & 2.10 & 1.75 & 1423.56 & 1.15 & - \\
\hline
\end{tabular}




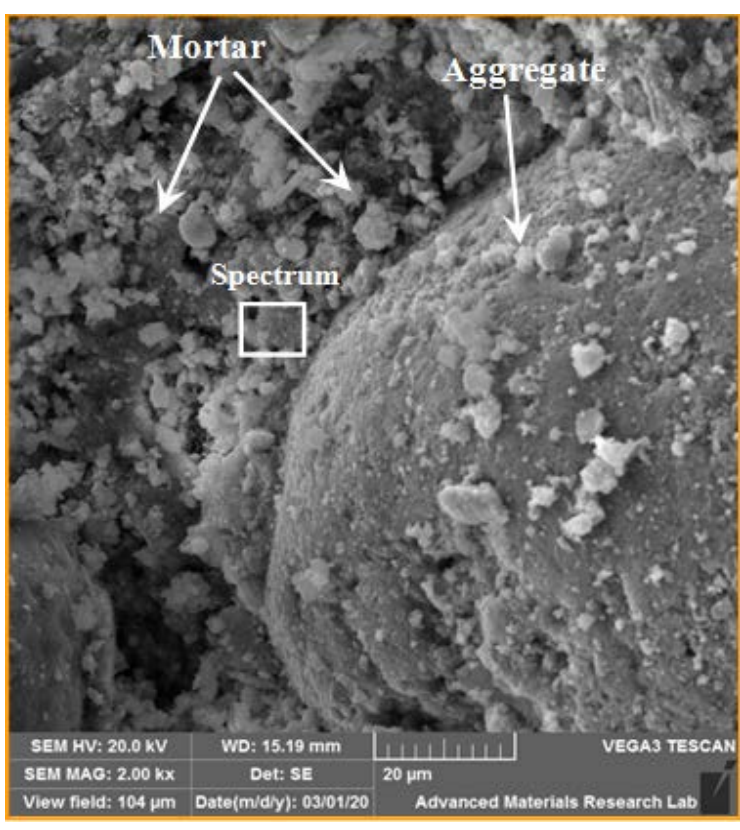

(a)

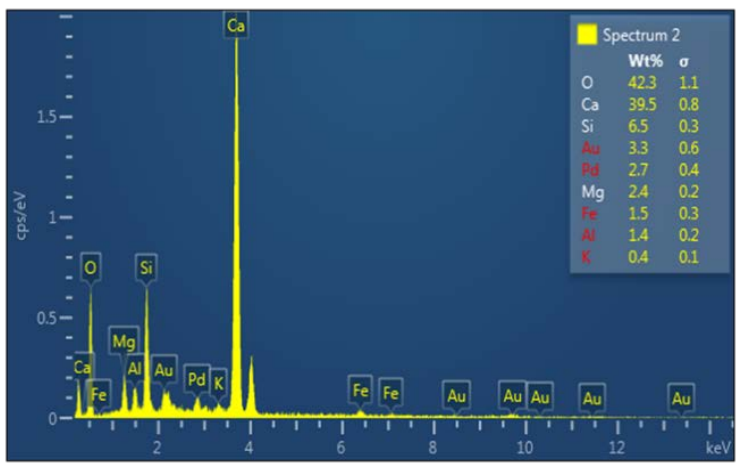

(b)

\subsection{Mixture Designs and Specimens}

Table 2 presents the composition of the eight concrete mixtures, four each produced using DS and CSS as fine aggregate at $0,25,50$, and 75 wt. \% replacement of NA with RA. All mixtures were produced according to the guidelines of ACI 211.1 (Standard Practice for Selecting Proportions for Normal, Heavyweight, and Mass Concrete). These mixtures were produced based on mix design for a $25 \mathrm{MPa}$ target compressive strength of the control mixtures in each category. The choice of the target compressive strength was based on the fact that 25 MPa compressive strength concrete is usually suitable for most of the structural members in reinforced concrete construction. The nomenclature of various concrete mixtures in Table 2 are defined such that; MDSR0 refer to concrete mixture produced with DS as fine aggregate, having $0 \%$ recycled aggregate. Similarly, MCSR25 refers to concrete mixture produced with CSS as fine aggregate, having 25 wt. \% of NA replaced with RA. In each category, mixture with 0 wt.\% replacement of NA with RA having respective fine aggregate is treated as control mixture for that category.

Cylindrical specimens having diameter of $100 \mathrm{~mm}$ and height of $200 \mathrm{~mm}$ were manufactured for compressive and split tension strength tests and static modulus of elasticity. Prism specimens having cross-section of $100 \mathrm{~mm} \times 100$ $\mathrm{mm}$ and a length of $400 \mathrm{~mm}$ were used for flexural strength test. While disc specimens cut from the concrete cylinders having thickness of $50 \mathrm{~mm}$ were used for water absorption test while $50 \mathrm{~mm}$ thick square specimens cut from the tested prism specimens were used for abrasion resistance test.

Figure 2. (a) SEM image of recycled aggregate (b) Energy dispersive spectra at the shown location

Table 2. Concrete mix designs

\begin{tabular}{|c|c|c|c|c|c|c|c|c|}
\hline Mix designation & $\begin{array}{c}\text { NA } \\
\left(\mathrm{kg} / \mathrm{m}^{3}\right)\end{array}$ & $\begin{array}{c}\text { RA } \\
\left(\mathrm{kg} / \mathrm{m}^{3}\right)\end{array}$ & $\begin{array}{c}\text { CSS } \\
\left(\mathrm{kg} / \mathrm{m}^{3}\right)\end{array}$ & $\begin{array}{c}\text { DS } \\
\left(\mathrm{kg} / \mathrm{m}^{3}\right)\end{array}$ & $\begin{array}{c}\text { Cement } \\
\left(\mathrm{kg} / \mathrm{m}^{3}\right)\end{array}$ & $\begin{array}{c}\text { Water } \\
\left(\mathrm{kg} / \mathrm{m}^{3}\right)\end{array}$ & $\begin{array}{c}\text { WRA* } \\
(\%)\end{array}$ & $\begin{array}{c}\text { W/c } \\
\text { MDSR0 }\end{array}$ \\
842.57 & 0 & 0 & 786.51 & 461.33 & 235.47 & 0.38 & 0.44 \\
\hline MDSR25 & 631.93 & 12.35 & 0 & 786.51 & 461.33 & 240.28 & 0.38 & 0.44 \\
\hline MDSR50 & 421.28 & 24.69 & 0 & 786.51 & 461.33 & 245.08 & 0.38 & 0.44 \\
\hline MDSR75 & 210.64 & 37.04 & 0 & 786.51 & 461.33 & 249.89 & 0.38 & 0.44 \\
\hline MCSR0 & 842.57 & 0 & 786.51 & 0 & 461.33 & 235.47 & 0.35 & 0.44 \\
\hline MCSR25 & 631.93 & 12.35 & 786.51 & 0 & 461.33 & 240.28 & 0.35 & 0.44 \\
\hline MCSR50 & 421.28 & 24.69 & 786.51 & 0 & 461.33 & 245.08 & 0.35 & 0.44 \\
\hline MCSR75 & 210.64 & 37.04 & 786.51 & 0 & 461.33 & 249.89 & 0.35 & 0.44 \\
\hline
\end{tabular}

* Water reducing agent used as weight \% of cement 


\subsection{Testing Procedures}

All tests were carried out following the procedures outlined in the relevant ASTM standards presented in Table 3. Slump test of fresh concrete mixtures was measured immediately after unloading the fresh concrete from the drum mixer. Compressive, flexural, and split tension strength tests were carried out at concrete age of 7 , 28 , and 56 days, while static modulus of elasticity was measured at concrete age of 90 days. Furthermore, water absorption and abrasion resistance of all concrete mixtures were measured at 56 days of concrete age. Abrasion resistance of all concrete mixtures was measured using ball bearing abrasion test machine shown in figure 3 . All test specimens were cured in lime saturated water in controlled laboratory environment until the age of testing. All test results represent a mean value of three specimen tests.

Table 3. ASTM specifications followed for various tests

\begin{tabular}{|l|c|}
\hline \multicolumn{1}{|c|}{ Test Name } & ASTM Standard \\
\hline $\begin{array}{l}\text { Specific gravity and water absorption of } \\
\text { coarse aggregate }\end{array}$ & ASTM C127 \\
\hline $\begin{array}{l}\text { Specific gravity and water absorption of } \\
\text { fine aggregate }\end{array}$ & ASTM C128 \\
\hline Slump test & ASTM C 143 \\
\hline Compressive strength & ASTM C 39 \\
\hline Flexural strength & ASTM C 78 \\
\hline Split tension strength & ASTM C 496 \\
\hline Abrasion resistance & ASTM C779 \\
\hline Static modulus of elasticity & ASTM C469 \\
\hline Water absorption test & ASTM C 1585 \\
\hline
\end{tabular}

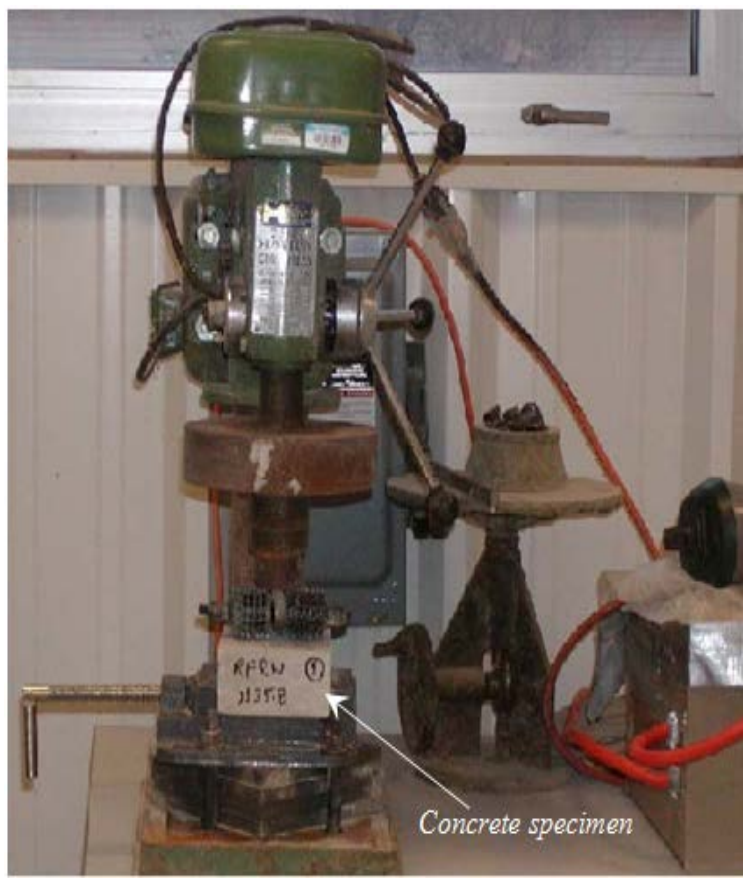

Figure 3. ASTM C 779 based test set up for abrasion resistance test

\section{Test Results and Discussions}

\subsection{Characteristics of Materials}

As can be seen in figure 1, DS comprises of extremely fine particles having almost uniform particle distribution as has been reported in earlier works [25]. Table 1 shows the extremely low fineness modulus of DS when compared with that of CSS (1.15 vs. 3.6). By contrast, CSS has a wide range of particle distribution with coarser particles having angular geometry. These characteristics of CSS make it a beneficial material towards formation of a dense concrete matrix. Due to the attachment of highly porous old mortar / paste to the aggregate particles of RA (figure 2), it has inferior physical and mechanical properties to that of NA as can be noticed from the Loss Angles abrasion and moisture absorption test results presented in Table 1.

\subsection{Fresh Concrete Properties}

As shown in Table 4 the CSS-based concrete mixtures show higher slump as compared to that of corresponding DS-based mixtures. This trend can be explained based on the fact that at same $w / c$ ratio, there is a higher number of fine particles in a unit weight of DS than that of CSS. More fine particles in a unit weight of concrete would require more cement paste to coat them, which will result into a net decrease in the quantity of paste, which acts as lubricant in the concrete mixture, resulting into loss of workability (slump) of the concrete mixture. This observation is line as reported by earlier researchers [21, 24]. Generally, in both categories of the concrete mixtures loss of slump occurred as the percent replacement of NA with RA increased, a trend that is in conformity with the findings of the earlier researchers [34,35]. Owing to the better packing density of particles and higher specific gravity of CSS than that of DS (Table 1), fresh concrete density of CS-based mixtures was higher than that of corresponding DS-based mixtures. Furthermore, an obvious trend in drop of fresh concrete density with increase in percent replacement of NA with RA was recorded in both categories of the mixtures.

Table 4. Results of slump and fresh concrete density tests

\begin{tabular}{|c|c|c|}
\hline Mix designation & Slump (mm) & $\begin{array}{c}\text { Fresh concrete density } \\
\left(\mathrm{kg} / \mathrm{m}^{3}\right)\end{array}$ \\
\hline MDSR0 & 65 & 5076 \\
\hline MDSR25 & 60 & 5002 \\
\hline MDSR50 & 55 & 4910 \\
\hline MDSR75 & 50 & 4875 \\
\hline MCSR0 & 75 & 5129 \\
\hline MCSR25 & 72 & 5063 \\
\hline MCSR50 & 65 & 4972 \\
\hline MCSR75 & 60 & 4923 \\
\hline
\end{tabular}




\subsection{Hardened Concrete Properties}

Figure 4 presents the test results of compressive strength test of all concrete mixtures at various concrete ages. The CS-based mixtures showed better compressive strength than that of corresponding DS-based mixtures. For example, at 28 days of concrete age, the compressive strength of MCSR25 mixture is about 10\% higher than that of MDSR25 mixture. At 56 days of concrete this difference is even higher. It is however noted that this effect was significant up to 50 wt.\% replacement of NA with RA. Beyond which the strength of the two types of mixtures are comparable. Improved packing density of CSS particles coupled with its filling effect result in formation of denser matrix in corresponding concrete mixtures resulting into superior compressive strength of CS-based concrete mixtures than that of DS-based mixtures, in which case this effect is minimal due to the particle size distribution of DS. At higher level of NA replacement with RA the concrete matrix densification effect brought about by the CSS particles is offset by the opposing effect of weakening of the matrix caused by the presence of large number of RA particles (figure 2). Hence, it is noted from figure 4 that MCSR75 mixture has nearly similar compressive strength as that of its counterpart MDSR75 mixture. Figure 4 further depicts that other than the control mixtures (MCSR0 \& MDSR0), the only mixture that achieved the target compressive strength of $25 \mathrm{MPa}$ at 28 days of concrete age was MCSR25. This observation highlights the fact that 25 wt.\% replacement of NA with RA might be the optimum level of replacement to achieve the target compressive strength.

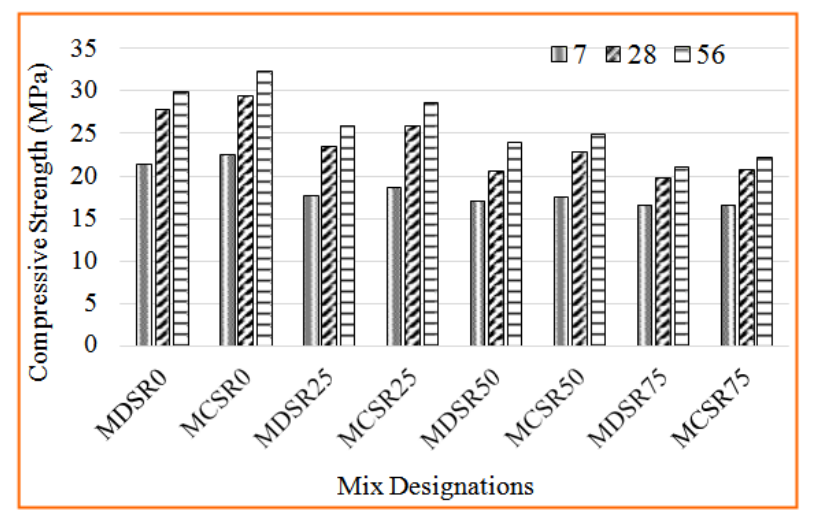

Figure 4. Compressive strength test results at various concrete age

Figure 5 shows the test results of flexural strength of all mixtures at 7, 28, and 56 days of concrete age. The results of flexural strength show similar trend to that of compressive strength. At 28 days of concrete age the flexural strength of MCSR50 mixture is about 15\% higher than its counterpart MDSR50 mixture. In this case too, the CS-based mixtures showed higher flexural strength than that of corresponding DS-based mixtures up to 50 wt.\% replacement of NA with RA beyond which there is no significant difference in the flexural strengths of the two categories of the mixtures. This trend is also attributed to the densification of matrix brought about by the presence of CSS which is nullified by the presence of large number of RA particles in concrete mixtures produced with higher level (> 50 wt. \%) of NA replacement with RA. In the case of flexural strength too, the mixture produced with $25 \mathrm{wt} . \%$ replacement of NA with RA (MCSR25) achieved a flexural strength of more than $4 \mathrm{MPa}$ at 28 days of concrete age which is considered a good design strength for structural concrete members subjected to bending. Although the flexural strength of MDSR25 mixture was close to $4 \mathrm{MPa}$ as well, yet it was about $7 \%$ less than that of its counterpart, MCSR25 mixture.

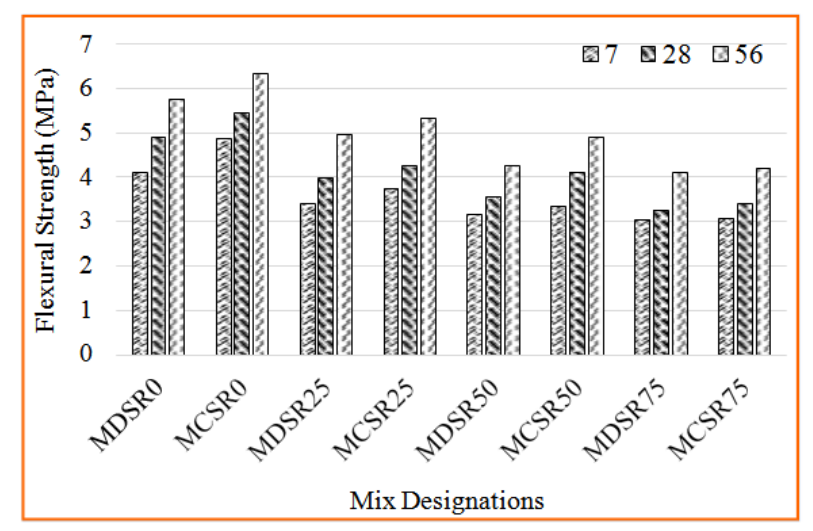

Figure 5. Flexural strength test results at various concrete age

Contrary to the trends observed in compressive and flexural strength test results, the split tension strength (figure 6) of the two categories of mixtures is closely similar at all levels of NA replacement with RA particularly up to 28 days of concrete age. Noting that improvement in split tension strength of concrete mixtures is largely dependent on improvement of their ITZ [4, 36], which is not a significant effect of CSS, resulting into closely similar split tension strength of both categories of mixtures. Test results of static modulus of elasticity test (figure 7) and abrasion resistance test (figure 8) could be explained based on the results of compressive strength test results, as static modulus of elasticity and abrasion resistance of concrete mixtures increase with increase in their compressive strength [3, 4, 37]. A strong linear correlation has also been reported between the abrasion resistance and flexural strength of concrete mixture in earlier investigations, as well [38]. Consequently, the trends found in figures $7 \& 8$ are in conformity with the findings of the earlier researchers. In this case too, the static modulus of elasticity and abrasion resistance test results of the two categories of concrete mixtures closely match at higher level of NA replacement with RA (> 50 wt. \%), a trend similar to that of compressive and flexural strength of these concrete mixtures. 


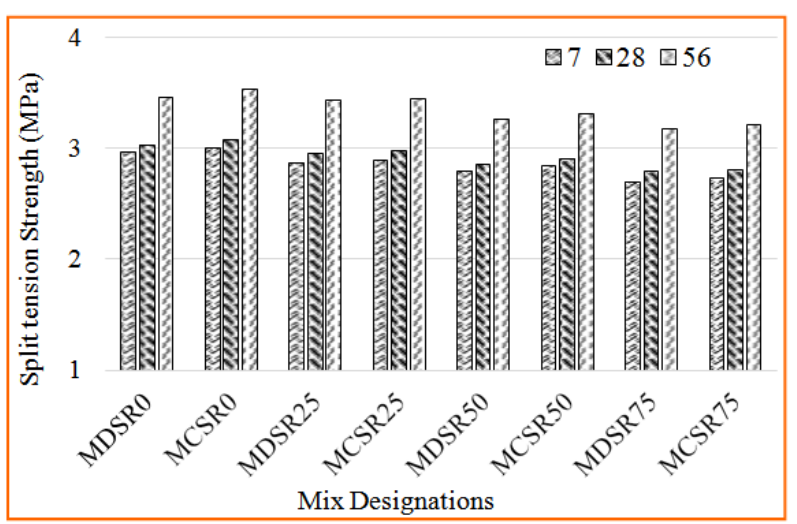

Figure 6. Split tension strength test results at various concrete age

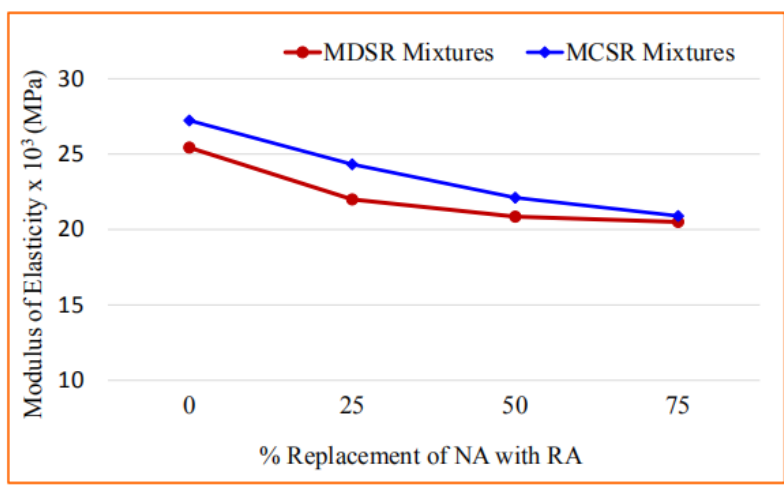

Figure 7. Static modulus of elasticity test results of DS and CSS based mixtures

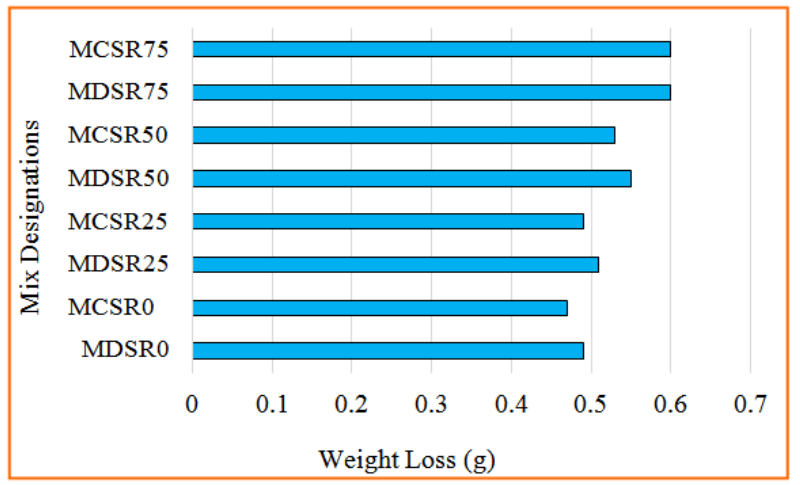

Figure 8. Abrasion resistance test results of DS and CSS based mixtures

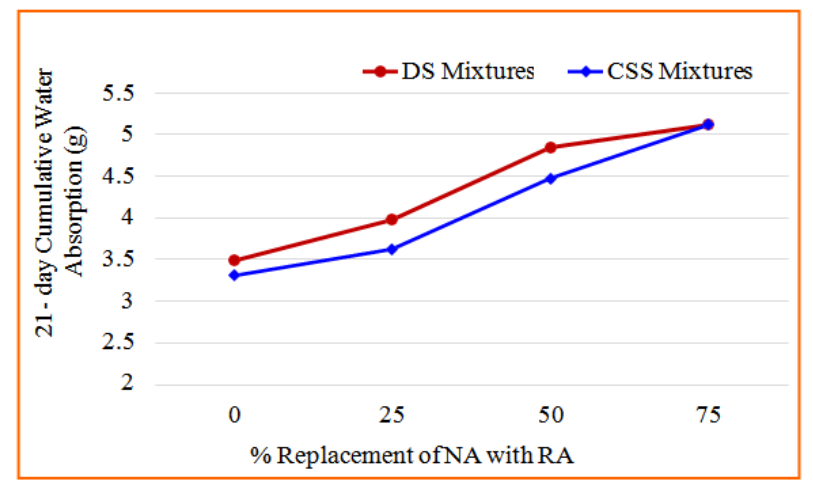

Figure 9. 21-day cumulative water absorption test results of DS and CSS based mixtures
Water absorption is an important indicator of durability of concrete materials. Long service life of concrete structures has direct relationship with the moisture barrier characteristics of concrete, it is made of $[4,7,16]$. It is noted from figure 9 that CS-based concrete mixtures showed significantly better moisture resistance characteristics during their 21 days exposure to water than that of DS-based concrete mixtures. About 10\% reduction in water absorption is recorded when test result of MDSR25 mixture is compared with that of MCSR25 mixture at 28 days of concrete age. At 50\% replacement level of NA with RA (MDSR50 vs. MCSR50), this reduction is recorded to be around $8 \%$. The superior performance of CS-based mixtures could be explained based on the filling and matrix densification effect realized in the relevant concrete mixtures through the presence of CSS. This effect was not significant in MCSR75 mixture when compared with its competitor MDSR75 mixture. In this case too, the weakening of matrix caused by the presence of large number of RA particles takes over the benefits of inclusion of CSS in the concrete mixtures.

\subsection{Microstructure Analysis}

It is to be noted that in RAC mixture two interfaces are formed. First one is found in RA between the aggregate and the clinging mortar / paste to it, whereas the second one is formed between RA and the new paste / mortar once RAC is produced. SEM images of the microstructure of MDSR25 and MCSR25 mixtures at 28 days of concrete age are shown in figure 10 . The dense and comparatively uniform microstructure of MCSR25 mixture (figure 10b) can be distinguished from a nonuniform and porous microstructure of MDSR25 mixture (figure 10a) which points at the filling and consequent densification effects of microstructure brought about by the inclusion of CSS. The detected difference between the microstructures of the two categories of the concrete mixtures is thought to be the leading cause of the superior performance of CS-based mixtures than those of DS-based mixtures.

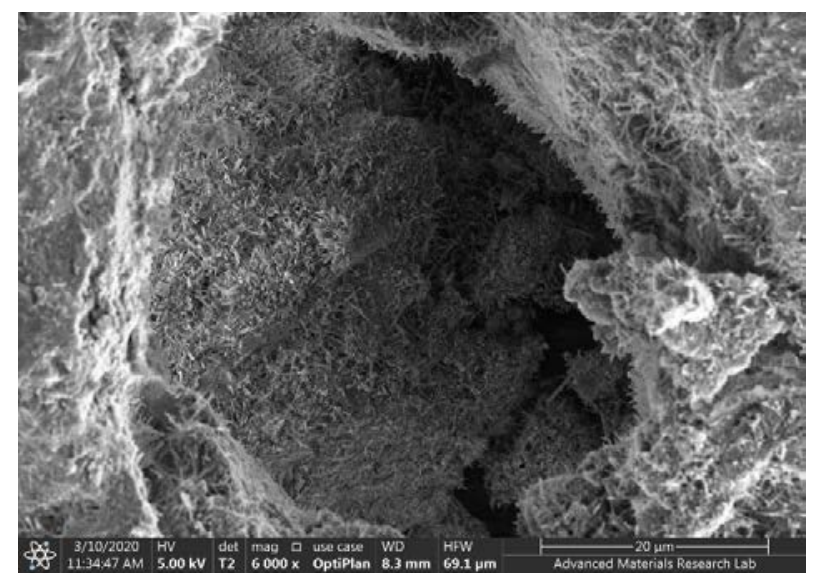

(a) 


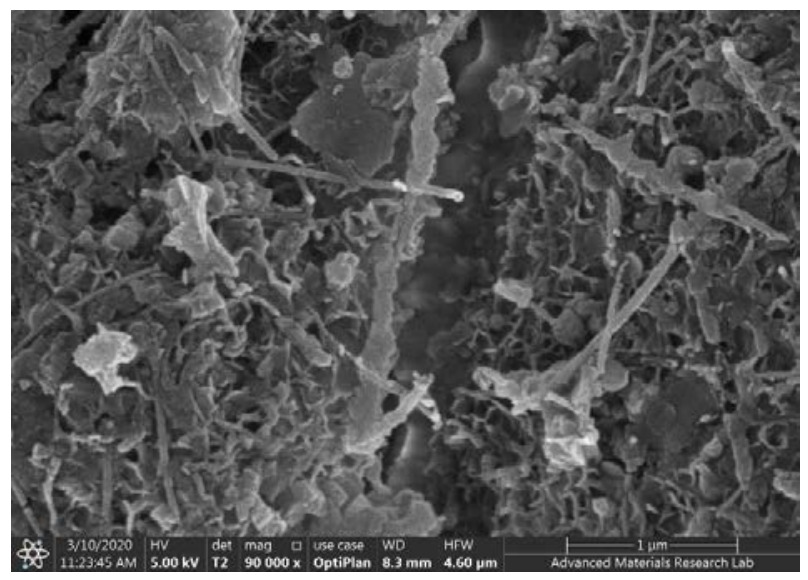

(b)

Figure 10. SEM image of microstructure of (a) MDSR25 mixture (b) MCSR25 mixture

\section{Conclusions}

To eliminate the limitations of the use of desert sand (DS) as fine aggregate in recycled aggregate concrete, the use of crushed stone sand (CSS) as fine aggregate at varying weight percentage replacement of natural aggregate (NA) with recycled aggregate (RA) was investigated in this research. Based on the test results of eight recycled aggregate concrete (RAC) mixtures and scanning electron imaging of selected mixtures, following conclusions are presented:

- $\quad$ The higher fineness modulus and angular geometry of larger CSS particles coupled with a wide range of particle size are beneficial characteristics that differentiate it from the much finer and uniform particle size distribution of DS.

- $\quad$ Use of CSS brought about filling and densification effect in the resulting concrete matrices which significantly benefitted the strength and durability characteristics of CS-based mixtures in comparison to that of DS-based mixtures.

- Compressive and flexural strengths and static modulus of elasticity of CS-based mixtures were significantly higher than that of corresponding DS-based RAC mixtures. Superior performance of CS-based mixtures is thought to be the result of improvement of microstructure realized through the inclusion of CSS as fine aggregate in these mixtures.

- $\quad$ Presence of CSS in RAC mixtures also benefitted the durability of resulting CS-based mixtures in the form of enhanced abrasion resistance and water barrier characteristics which were recorded to be significantly higher for CS-based mixtures than that of DS-based mixtures.

- $\quad$ No noticeable effect of CSS on split tension strength of RAC mixtures was recorded. This may be due to the fact that enhancement in split tension strength is highly dependent on the improvement of ITZ which is not a direct effect of the inclusion of CSS in concrete mixtures.

- $\quad$ At higher level of replacement (>50 wt. \%) of NA with RA, the beneficial effects of the use of CSS as fine aggregate for production of RAC are neutralized by the opposing effect caused by the presence of large number of weak RA particles that result in weakening the microstructure / matrix of concrete mixture. Therefore, the strength and durability performance of the two categories of RAC mixtures was quite comparable at 75 wt. \% replacement of NA with RA. It is therefore concluded that 25 wt.\% replacement of NA with RA for production of RAC mixtures with CSS used as fine aggregate may be an optimum replacement level.

- $\quad$ Comparison of the SEM images of the MCSR25 and MDSR25 mixtures showed that the inclusion of CSS resulted in formation of a uniform and denser microstructure of MCSR25 mixture when compared with that of MDSR25 mixture.

\section{REFERENCES}

[1] Green cement Production has a Big Role to Play in Reducing Greenhouse Gas Emissions 2010, United Nations Environment Programme: New York.

[2] Concrete is more than a material: It's about life. 2019, Global Cement and Concrete Association.

[3] M., N.A., Properties of Concrete. Fifth ed. 2011: Pearson Education Limited.

[4] Mehta, P.K., Monteiro, P.J.M, Concrete: Microstructure, Properties, and Materials. Fourth ed. 2014: McGraw Hill Education.

[5] Mechanical and durability properties of concrete based on recycled coarse and fine aggregates produced from demolished concrete. Construction and Building Materials, 2020. 246: p. 118421.

[6] Suitability of recycled concrete aggregates from precast panel buildings deconstructed at expired lifespan for structural use. Journal of Cleaner Production, 2020. 247: p. 119593.

[7] Nassar, R.-U.-D. and P. Soroushian, Strength and durability of recycled aggregate concrete containing milled glass as partial replacement for cement. Construction and Building Materials, 2012. 29: p. 368-377.

[8] Portland Cement Association, 2016. "Recycled Aggregate". https://www.cement.org/learn/concrete-technology/concret e-design-production/recycled-aggregates\#

[9] Lamond, Joseph F. et al. "Removal and Reuse of Hardened Concrete.” 2001, (Report No. ACI 555R-01), American Concrete Institute. 
[10] Development, W.B.C.f.S., The Cement Sustainability Initiative - Recycling Concrete 2009, World Business Council for Sustainable Development. p. 42.

[11] Macro- and micro- properties of multi-recycled aggregate concrete. Journal of Cleaner Production, 2020. 245: p. 118843.

[12] C., M., Concrete and Sustainable Development. ACI Special Publications, ACI 206, 2002.

[13] Chloride permeability of recycled aggregate concrete under the coupling effect of freezing-thawing, elevated temperature or mechanical damage. Construction and Building Materials, 2020. 237: p. 117648.

[14] An industrial applicable method to improve the properties of recycled aggregate concrete by incorporating nano-silica and micro-CaCO3. Journal of Cleaner Production, 2020. 259: p. 120920.

[15] Performance assessment of concrete incorporating recycled coarse aggregates and metakaolin: A systematic approach. Construction and Building Materials, 2020. 233: p. 117223.

[16] Nassar, R.-U.-D. and P. Soroushian, Use of milled waste glass in recycled aggregate concrete. Proceedings of the Institution of Civil Engineers - Construction Materials, 2013. 166(5): p. 304-315.

[17] Mehta, P.K., Greening of the Concrete Industry for Sustainable Development. Concrete International. 24(7).

[18] Miller, S., Supplementary cementitious materials to mitigate greenhouse gas emissions from concrete: can there be too much of a good thing? Journal of Cleaner Production, 2018. 178.

[19] Faleschini, F., M. Zanini, and C. Pellegrino, Environmental impacts of recycled aggregate concrete. 2016.

[20] Pavlů, T., V. Kočí, and P. Hájek, Environmental Assessment of Two Use Cycles of Recycled Aggregate Concrete. Sustainability, 2019. 11(21): p. 6185.

[21] Al-Harthy, A.S., et al., The properties of concrete made with fine dune sand. Construction and Building Materials, 2007. 21(8): p. 1803-1808.

[22] Bouziani, T., M. Bederina, and M. Hadjoudja, Effect of Dune Sand on the Properties of Flowing Sand-Concrete (FSC). International Journal of Concrete Structures and Materials, 2012. 6.

[23] Zhang, G., et al., Performance of mortar and concrete made with a fine aggregate of desert sand. Building and Environment, 2006. 41(11): p. 1478-1481.

[24] Seif, E.-S.S.A., Assessing the engineering properties of concrete made with fine dune sands: an experimental study. Arabian Journal of Geosciences, 2013. 6(3): p. 857-863.
[25] Tsoar, H., The physical properties of desert dune sand and its ecological implications. Aarhus Geoscience, 1997. 7: p. 79-90.

[26] Haifeng, L., et al., Influence of desert sand on the mechanical properties of concrete subjected to impact loading. Acta Mechanica Solida Sinica, 2017. 30(6): p. 583-595.

[27] Jin, B.H., J.X. Song, and H.F. Liu, Engineering Characteristics of Concrete Made of Desert Sand from Maowusu Sandy Land. Applied Mechanics and Materials, 2012. 174-177: p. 604-607.

[28] Lynda Amel, C., et al., Dune sand and pumice impact on mechanical and thermal lightweight concrete properties. Construction and Building Materials, 2017. 133: p. 209-218.

[29] Rayasam, R., Even desert city Dubai imports its sand. This is why. 2016, BBC Worklife.

[30] Kaigama, W. and O. Samson O, Effect of Using Recycled Concrete Aggregate as a Replacement of Crushed Stone in Concrete Production. 2011.

[31] Prasetia, I. and A. Maulana, Effects of crushed stone waste as fine aggregate on mortar and concrete properties. IOP Conference Series: Materials Science and Engineering, 2019. 620: p. 012040

[32] Kou, S.-C. and C.-S. Poon, Properties of concrete prepared with crushed fine stone, furnace bottom ash and fine recycled aggregate as fine aggregates. Construction and Building Materials, 2009. 23(8): p. 2877-2886.

[33] Shen, W., et al., Influence of manufactured sand's characteristics on its concrete performance. Construction and Building Materials, 2018. 172: p. 574-583.

[34] Lavado, J., et al., Fresh properties of recycled aggregate concrete. Construction and Building Materials, 2020. 233: p. 117322.

[35] Silva, R.V., J. de Brito, and R.K. Dhir, Fresh-state performance of recycled aggregate concrete: A review. Construction and Building Materials, 2018. 178: p. 19-31.

[36] Mindess S., Y.J.F., Darwin D., Concrete. Second ed. 2002: Prentice Hall.

[37] Singh, G. and R. Siddique, Abrasion resistance and strength properties of concrete containing waste foundry sand (WFS). Construction and Building Materials, 2012. 28(1): p. 421-426.

[38] Atis, C., et al., Relation between Strength Properties (Flexural and Compressive) and Abrasion Resistance of Fiber (Steel and Polypropylene) Reinforced Fly Ash Concrete. Journal of Materials in Civil Engineering - J MATER CIVIL ENG, 2009. 21. 